\title{
Grieks vir Nuwe Testament: 'n Nuwe paradigma aan Suid-Afrikaanse universiteite vir die onderrig van Grieks met die oog op teologie
}

Fika J van Rensburg \& Hendrik F Stander

Slool vir Bybelwetenslappe en Bybeltale PU vir CHO

\& Depertement Antiele Tale (Grielss)

Universiteit van Pretoria

\begin{abstract}
Greek for the New Testament: A new paradigm at South African Universities for the teaching of Greek for Theology

The faculty members of the departments of Greek and New Testament of a number of South African Universities have since 1995 been involved in discussions on the teaching of Greek to students who want to study Theology. This article is an updated version of the memorandum the two authors tabled for the discussion. The memorandum was discussed in 1996, and during the 1997 meeting it was finalised. The article gives an overview of the consensus achieved. First an analysis of the present situation is given (2), on the grounds of which the need for a change in approach is motivated (3). Then the outcomes for the teaching of Greek are discussed (4). Appropriate methods of learning and teaching are proposed (5) as well as methods of evaluation (6). It is also argued that the Universities have the obligation to provide Greek scholars for the future (7). The article closes with a plea for closer co-operation between Greek and New Testament departments at South African Universities (8).
\end{abstract}

\section{INLEDDNG}

Die personeel van die Departemente Grieks en Nuwe Testament an enkele SuidAfrikaanse Universiteite ${ }^{1}$ was sedert 1995 met meicaar in gesprek oor die onderrig van Grieks aan studente wat die Nuwe Testament wil bestudeer. Die outeurs van hierdie artikel het opdrag gehad om 'n memorandum uit te werk. Dit is gedurende 1996 bespreek, en tydens die 1997-vergadering is die gesprek tot finaliteit gebring. Dié artikel vat die essensie van die konsensis saam. 
Die aanpak is die volgende:

* Situasie-analise.

* 'n Koersaanpassing.

* Uitkomste vir die onderrigleer van Grieks.

* Onderrigleermetodes.

* Evaluering.

* Behoefte aan Grieks-kundiges.

* Samewerking tussen Grieks en Nuwe Testament.

\section{SITUASIE-ANALISE}

\subsection{Behoeftes van die kerke}

Die gemeenskap wat tans vir die opleiding in Grieks ter sake is, is die verskillende kerke. Kerke vereis dat bedienaars van die Woord oor die vermoë beskik om op 'n gëldige en verantwoordelike wyse die Nuwe Testament (en natuurlik ook die Ou Testament) te interpreteer en vir die gelowiges toe te pas. Hiertoe vereis baie kerke (in elk geval dié wat by die huidige gesprek betrokke is) dat voornemende bedienaars van die Woord vir hulle teologiese studies Grieks tot op ten minste vlak II neem. Die verwagting by die huidige grootste 'kliënt' van die departemente wat Grieks aanbied, is dus dat 'n student wat Grieks tot op Vlak II verwerf het, oor die minimumtoerusting beskik op grond waarvan die opleiding in Nuwe Testament suksesvol kan plaasvind.

\subsection{Uitkomste deur beroepe genoodsaak}

Studente wat vir opleiding in Grieks aanmeld, bevind hulleself uiteindelik in een van die volgende drie beroepe: bedienaar van die Woord, Bybelvertaler en dosent. Vir al drie gevalle is die hoofuitkoms dat die betrokke beroepsbekleder die Griekse Nuwe Testament selfstandig geldig kan interpreteer vir mense wat hulle in die vroeg 21 ste eeuse Suid-Afrikaanse sosio-politieke situasie bevind.

\subsection{Vermoëns waarmee studente inskryf}

Oor die algemeen is die vermoëns van (voor-)teologiese studente gemiddeld tot goed. Van tyd tot tyd skryf persone in wat uitsonderlik begaafd is, waarvan die meeste Grieks tot op vlak III en nagraads neem. Dit is opmerklik dat daar tans feitlik geen studente meer is wat inskryf met 'n matriekkwalifikasie in tale soos Latyn of Duits nie. Dit hou in dat geen kennis van die struktuur van 'n klassieke taal veronderstel kan word nie. Dit is verder ' $n$ tendens dat daar al meer persone inskryf en wil inskryf uit 'n skoolagtergrond met duidelik aanwysbare agterstande. 


\subsection{Gesindheid van studente}

Die gesindheid van studente is oor die algemeen positief en hulle is gemotiveerd om hard te werk. Die voorwaarde is egter dat die dosent entoesiasties moet wees, die kursus goed gestruktureerd, georganiseerd en realisties haalbaar moet wees, en veral dat die relevansie van die kursusinhoud vir die uiteindelike interpretasie van die Griekse Nuwe Testament, nie net duidelik moet wees nie, maar ook proefondervindelik deur die student ervaar moet word. Die relevansie moet nie net 'n tipe Kanaän-belofte wees wat die nodige stamina vir die woestynreis moet voorsien nie. As daar nie genoeg manna (in die vorm van proefondervindelike ervaring van die relevansie van die Grieks vir die verstaan van die Nuwe Testament) is nie, raak die student in elk geval na Grieks II vir Grieks en dikwels ook vir Nuwe Testament weg.

\subsection{Terugvoer vanaf predikante}

Terugvoer van predikante oor 'n breë front dui daarop dat 'n baie klein persentasie predikante ná hulle teologiese studies hulle interpretasie van die Nuwe Testament op grond van die Griekse teks doen. Baie vingers kan elders heen (sekondêre onderwys, tydgees) gewys word, maar selfondersoek deur Grieks-dosente is gepas. Aan die tydgees kan kwalik verander word; wat wel binne ons beheer lê, is om die onderrig binne die beperkings van die tydgees te optimaliseer. Dit is waarop die res van hierdie dokument mik.

\subsection{Onderrigleeruitkomste en wyse van evaluering}

In praktyk is die onderrigleeruitkoms in baie gevalle dat 'n suksesvolle Grieks-student Grieks moet kan lees. Dit hou in dat sodanige persoon 'n perikoop uit die Nuwe Testament sonder hulpmiddels moet kan vertaal en woorde en konstruksies moet kan ontleed en verklaar.

Dit is ' $n$ onrealistiese uitkoms en nie haalbaar in die minimum van twee jaar opleiding nie, veral gesien die feit dat dit juis die swakker student is wat Grieks slegs tot op vlak II neem. Die gevolg van hierdie benadering was dat baie bedienaars, alhoewel hulle Grieks II formeel verwerf het, hulleself nie toegerus gevoel het om hulle interpretasiewerk op grond van die Griekse Nuwe Testament te doen nie, en dat die Griekse Nuwe Testament dan inderdaad opsy geskuif is. Die tydinset wat die betrokke interpreteerder moet maak, is uit sy eie persepsie net nie die geringe dividend werd nie.

Hierdie tipe onderrigleeruitkoms mond ook uit in 'n wyse van evaluering (sowel by Grieks as by Nuwe Testament) waar 'n praktykvreemde (bedoelende: die bedieningspraktyk van die predikant) evalueringsituasie geskep word. Die kandidaat moet in twee of drie ure sonder hulpmiddels vrae beantwoord oor werk wat in die klas of tuis voorberei is. Die praktykvreemdheid le daarin dat studente nooit as predikant met 'n kaal 
Griekse teks sonder hulpmiddels sal werk nie. Hulle gaan by hulle lessenaar sit, met (verskeie) vertalings van die Nuwe Testament tot hulle beskikking, ascok ten minste woordeboeke en grammatikaboeke, en deesdae ook al hoe meer met rekenaarmatige. hulpmiddels soos die Logos-programmatuur.

Die praktykvreemdheid van die evalueringsituasie (en die aard van die vraestel) werk in die hand dat studente hulle korttermyngeheue met 'n groot tydinset inspan, en op grond daarvan tog deurkom. Omdat dit egter blote reproduksievermoe is wat geèvalueer word, is dit in baie gevalle ook al vermoë wat studente aanleer. Dit lyk dus noodsaaklik dat Grieks-aanbieders nie net die onderrigleeruitkoms hersien nie, maar dat ook die wyse van evaluering daarmee saam krities herdink moet word.

\section{3. 'N KOERSAANPASSING}

Die voorafgaande situasie-analise maak dit noodsaaklik om die onderrigleeruitkoms van Grieks (in elk geval voorgraads, en ten minste tot op vlak II) en in sekere opsigte ook dié van Nuwe Testament te verander. Die (onhaalbare!) uitkoms moenie meer wees dat 'n suksesvolle Grieks-kandidaat antieke Griekse tekste (by name die Griekse Nuwe Testament) moet kan lees nie, maar dat hy/sy dit op grond van kennis van en vaardigheid met al die beskikbare hulpmiddels geldig moet kan interpreteer.

Die klem in die onderrig moet dus verskuif weg van die blote memorisering van bepaalde data (asof die predikant sonder hulpmiddels met die Griekse Nuwe Testament moet werk), na die aankweek van 'n vermoë om Griekse tekste (veral die Griekse Nuwe Testament) geldig te interpreteer. ${ }^{2}$ Natuurlik is daar minima wat gememoriseer moet word. Hierdie minima moet geidentifiseer word, maar moet slegs 'n middel tot die bereiking van die uitkoms wees, en nooit die uitkoms self word nie.

\section{UTTKOMSTE VIR DIE ONDERRIGLEER VAN GRIEKS}

\subsection{Oorkoepelende uitkomste}

In die lig van die bostaande kan die uitkomste vir die onderrigleer van Grieks (in elk geval tot op vlak II) die volgende wees:

* Die studente moet toegerus wees in Grieks as wetenskap met die oog op die interpretasie van die Griekse Nuwe Testament vir die verskillende beroepsmoontlikhede. 
* Die studente moet vennote in die onderrigleerproses wees, en so 'n uitkomsgeoriënteerde opvoedkundige gemeenskap vorm, waar personeel en studente dieselfde akademiese uitkomste nastreef, en waar hulle saamwerk om die onderrig en studie te versterk.

* Die onderrigleer moet só geskied dat, afgesien van die bereiking van akademiese uitkomste, daar ook geloofsverryking plaasvind. Kandidate moet in hulle akademiese arbeid die relevansie van hulle werk vir die alledaagse lewe asook vir hulle beroep besef en beleef.

* Die studente moet op emosionele en persoonlikheidsvlak tot volle potensiaal ontwikkel wees, asook ten opsigte van geestelike groei in die persoonlike verhouding met God en diens tot die naaste, onder andere met betrekking tot die roeping om voltyds bedienaar van die Woord te wees.

* In die uitvoering van bogenoemde moet daar vir studente rolmodelle wees, onder andere deurdat die samestelling van die studentekorps gereflekteer word in die dosentekorps.

\subsection{Jaarvlakuitkomste}

\subsubsection{Algemeen}

Die onderrigleeruitkomste behoort beslissend bepaal te word deur die feit dat vir praktiese doeleindes $100 \%$ van die kandidate of (voor-)teologiese studente is of in elk geval Grieks neem met die oog op toerusting vir die interpretasie van die Griekse Nuwe Testament. 'n Verdere belangrike vertrekpunt (waarin onderrigleer in Grieks anders is as dié in moderne tale) is dat die onderrigleer daarop gemik is om studente toe te rus om reeds gegenereerde antieke Griekse tekste te interpreteer, en nie om Griekse te!'ste te genereer nie.

Die hoofuitkoms kan derhalwe wees dat suksesvolle kandidate 'n antieke Griekse teks, in besonder die Griekse Nuwe Testament, verantwoordelik deur gebruikmaking van alle geskikte hulpmiddels (insluitend rekenaarmatige hulpmiddels) moet kan interpreteer op die terrein van Griekse morfologie en sintaksis, semantiek, literatuurkunde en sosio-historiese konteks. ${ }^{3}$

Op vlak I word die llem gele op die aanleer van die basiese Griekse grammatika en die vermoe om Griekse vorms en konstruksies te ontleed ${ }^{4}$ en te verklaar. ${ }^{5}$ Op vlak II en III verskuif die klem na die ontwikkeling van die vermoe om Griekse vorms en konstruksies ook te interpreteer. 


\subsubsection{Grieks op vlak I}

Die uitkoms is dat elke suksesvolle kandidaat die fasette van die Griekse taal wat in die handboek Grieks met Begrip behandel word, so bemeester dat geselekteerde onvoorbereide gedeeltes uit die Griekse Nuwe Testament op 'n elementêre wyse op grond van die gebruikmaking van hulpmiddels geinterpreteer kan word, en dat hierdie interpretasie grammatikaal gemotiveer kan word. Dit is noodsaaklik dat die studente reeds hier proefondervindelik ervaar wat die waarde van die bestudering van Grieks vir die verstaan van die Nuwe Testament is.

\subsubsection{Grieks op vlak II}

Die oorkoepelende uitkoms kan wees dat elke suksesvolle kandidaat 'n perikoop uit die Griekse Nuwe Testament en verwante Griekse tekste met hulpmiddels op 'n geldige en kontroleerbare wyse filologies moet kan interpreteer.

Die komponente waaruit die kursus kan bestaan, is 'n grammatikakomponent, 'n sosio-historiese komponent, 'n semantiekkomponent, 'n teksontledingskomponent, 'n rekenaargeletterdheidskomponent, en 'n gerigte metodologie-komponent.

Die spesifieke uitkomste van die kursus kan byvoorbeeld wees dat elke suksesvolle kandidaat:

* 'n oorsig het oor die grammatika van die Griekse Nuwe Testament;

* 'n oorsig het oor die sosio-historiese konteks van die Nuwe Testament;

* georiènteer is ten opsigte van die interdissiplinêre aard van die studie van die Griekse Nuwe Testament;

* 'n oorsig het oor die basiese semantiese beginsels wat betrokke is by die interpretasie van 'n Griekse teks, en spesifiek in staat is om die beginsels vir die bepaling van betekenis op woordvlak, en sins- en perikoopvlak prakties toe te pas;

* ten opsigte van teksontleding kan die doelwitte wees dat elke kandidaat:

- insig het in die stand van sake ten opsigte van die ontleding van Griekse tekste; 
- die relasiemoontlikhede van die onderdele van 'n sin met mekaar, en ook die relasiemoontlikhede tussen die betekeniskomponente van 'n taaluiting ken, dit in 'n Griekse teks (met die hulp van vertalings) herken, en die Griekse teks kan herskryf sodat die relasies visueel voorgestel word;

- die gedagte-opbou van 'n perikoop uit die Griekse Nuwe Testament op mikroen op makrovlak selfstandig kan bepaal, en in staat is om sodanige resultaat ten opsigte van 'n perikoop as ' $\mathrm{n}$ werkstuk van beperkte omvang. aan te bied.

* vertroud is met rekenaarprogramme wat as hulpmiddels by die interpretasie van die Griekse Nuwe Testament gebruik kan word, en dit ook self effektief gebruik.

* dat die kandidaat met ' $n$ bepaalde metodologie wat vir die interpretasie van die Griekse Nuwe Testament tersaaklik is, vertroud is.

\section{Epistolografie as voorbeeld:}

Die corkoepelende uitkoms is dat die student in staat is om epistolografie as metode tot die interpretasie van Griekse tekste toe te pas en 'n geldige interpretasie op grond hiervan teen die breê sosio-historiese konteks te maak.

Dit kan in twee spesifieke uitkomste verdeel word, naamlik (1) dat die student kennis het van die basiese aspekte van die antieke epistolografiese teorie en praktyk, en (2) 'n vaardigheid het in die interpretasie van antieke briewe.

\subsubsection{Grieks op vlak III}

Die corkoepelende uitkoms met Grieks op vlak III kan wees dat elke suksesvolle kandidaat 'n (gedeelte van 'n) boek uit die Griekse Nuwe Testament met hulpmiddels op 'n geldige en kontroleerbare wyse moet kan interpreteer.

Die komponente waaruit die kursus kan bestaan, is 'n sintaksiskomponent, 'n teksontledingskomponent, 'n rekenaargeletterdheidskomponent, en een of meer gerigte metodologiekomponente.

Die doelwitte van die sintaksiskomponent van die kursus kan wees dat elke kandidaat:

* insig het in die stand van sake ten opsigte van Griekse grammatikas met betrekking tot die Griekse Nuwe Testament;

* 'n oorsig het oor die morfologie en sintaksis van die Griekse Nuwe Testament; 
* die grammatika van Blass-Debrunner-Funk (totdat 'n beter een beskikbaar kom) suksesvol kan gebruik in die interpretasie van die Griekse Nuwe Testament;

* in staat is om selfstandig navorsing te doen oor 'n spesifieke onderdeel van die Griekse grammatika, en die navorsing as 'n werkstuk van beperkte omvang aan te bied.

Die uitkoms van die teksontledingkomponent van die kursus kan wees dat elke kandidaat die gedagte-opbou van 'n brief van die Griekse Nuwe Testament op mikro- en op makrovlak op grond van die bepaling van die intrasin asook die relasies tussen gedagtekomponente daarvan selfstandig moet kan bepaal, en die resultaat ten opsigte van 'n perikoop as 'n werkstuk van beperkte omvang aanbied.

Die uitkomste van die rekenaargeletterdheidskomponent van die kursus kan wees dat elke kandidaat:

* insig het in die stand van sake ten opsigte van rekenaarprogramme wat as hulpmiddels by die interpretasie van die Griekse Nuwe Testament beskikbaar is;

* vertroud is met die program Online Bible en die Logos-programmatuur;

* kennis het van multimedia-programme, byvoorbeeld Out of the tombs, Mark en The Visit van die American Bible Society;

* genoemde programme effektief as hulpmiddels by fasette van die interpretasie van Griekse tekste moet kan gebruik.

Die uitkoms met die gerigte metodologie-komponent(e) kan wees dat die kandidaat met 'n bepaalde metodologie wat vir die interpretasie van die Griekse Nuwe Testament tersaaklik is, vertroud is.

Morele aansporing in die eerste eeu as eerste voorbeeld van 'n gerigte metodologiekomponent:

Die corkoepelende uitkoms is dat die student die morele aansporing wat in die Nuwe Testament voorkom, in sosio-historiese en literére reliëf moet kan plaas. 
Die spesifieke uitkomste met hierdie onderdeel van die kursus is dat elke kandidaat, op grond van die primère Griekse tekste, insig het in die sosiale konteks van morele onderrig, die oogmerke en eienskappe van die morele opvoeder, die metodes van onderrig en morele begeleiding, die onderrigwyses, die aansporingstyle, die tersaaklike literkre en retoriese konvensies, en die tipiese temas van die morele aansporing.

Antieke retoriek as tweede voorbeeld van 'n gerigte metodologiekomponent:

Die oorkoepelende uitkoms is dat die student enige teks aan die hand van die antieke retoriese sisteem moet kan interpreteer. Hierdie tekste sluit antieke Griekse tekste asook moderne tekste soos films, toesprake, advertensies, ensovoorts in.

Die spesifieke uitkomste van die kursus is dat elke kandidaat: (1) 'n oorsig het oor die ontwikkeling van die antieke retoriese sisteem; (2) kennis het van die inhoud van die antieke retoriese sisteem; (3) vertroud is met die tekste van veral Aristoteles oor die antieke retoriek; (4) in staat is om die verworwe kennis prakties in die interpretasie van tekste (waaronder veral die Griekse Nuwe Testament) toe te pas.

\section{ONDERRIGLEERMETODES}

Dosente moenie die funksie van blote 'oordraers van kennis' vervul nie, maar van 'bestuurders van die onderrigleer' in 'n bron-gebaseerde onderrigmodel. Dus behoort kontakgeleenthede hoofsaaklik ingerig te word as seminaarklasse. Dit hou in dat die kandidate selfstandig voor en vir die kontakgeleentheid die werk voorberei (of die bepaalde afspraak in verband met RGO nakom) soos in die studiegids gespesifiseer. Die dosent kan dan 'n kort inleiding gee oor die gespesifiseerde onderwerp(e) waama daar geleentheid is vir inligtingsvrae en/of diskussie.

\section{EVALUERING}

Evaluering moet die graad van sukses waarmee die gespesifiseerde uitkomste bereik is, meet. Nie die retensie- en reproduksievermoë van 'n kandidaat moet dus geëvalueer word nie, maar die vermoë om antieke Griekse tekste op grond van die beskikbare hulpmiddels geldig te interpreteer.

In praktyk kom dit daarop neer dat klaswerk (voorbereide werk) nie in die finale evaluering aan die orde moet kom nie, maar dat die aangeleerde interpretasievermoëns op grond van geselekteerde onvoorbereide gedeeltes uit die Nuwe Testament en ander tekste getoets word. Dit moet 'n oopboek-eksamen wees, en sonder 'n werklike tyds- 
beperking. Fasette van die kursus wat wel gememoriseer moet word, kan by wyse van kleiner onderrigtoetse geëvalueer word.

\section{BEHOEFTE AAN GRIEKS-KUNDIGES}

Hierdie verrekening van die 'situasie' mag nie daartoe lei dat daar geen Griekskundiges in die klassieke sin van die woord opgelei word nie. Dit wil slegs pleit daarvoor dat daar nie 'n poging moet wees om elke voomemende predikant dit te wil maak nie. Wat wel in praktyk moet gebeur, is dat individue met besondere aanleg geidentifiseer moet word, en aangemoedig moet word (met beurse, ook uit 'kerk'-geld) om 'n Griekskundige in die klassieke sin van die woord te word. Sonder 'n beduidende korpus sulke persone, sal die studie van Grieks en die Nuwe-Testamentiese wetenskap in Suid-Afrika veragter.

\section{SAMEWERKING TUSSEN GRIEKS EN NUWE TESTAMENT}

Op elke kampus mót weë gevind word om die samewerking tussen Grieks en Nuwe Testament te optimaliseer. Hierdie samewerking is noodsaaklik vir albei die dissiplines. Die samewerking en vennootskaplikheid moet idealiter uitmond in 'n sigbare dinamiese navorsingsgemeenskap, sigbaar ook en veral vir studente.

Nagraadse studente moet ook in hierdie navorsingsgemeenskap betrek word. Só sal studente tot die breër terrein aangetrek word, en werk almal mee tot die uitbouing van die interafhanklike navorsingsterreine van Grieks en Nuwe Testament in die SuidAfrikaanse situasie.

\section{Endnotas}

1 Die betrokke departemente van die volgende Universiteite was betrokke: Potchefstroomse Universiteit vir Christelike Hoër Onderwys, Universiteit van Pretoria, Universiteit van die Oranje Vrystaat, Universiteit van Stellenbosch, Universiteit van Wes-Kaap en Rands Afrikaanse Universiteit.

2 Sodanige koerseanpassing sal enersyds 'n baie groter entoesiasme by huidige studente veroorsaak (met gevolglike ansienlike toename in studentegetalle vir Grieks op vlak III en potensieel cok vir Grieks Honneurs, en M- \& D-studie in Grieks en Nuwe Testament). Andersyds sal 'n gevolg wees dat oudstudente bulleself meer toegerus voel om die Griekse Nuwe Testament te interpreteer en sal hulle dit ook met groot welslae doen. Dit sal hulle aanmoedig om steeds met die Griekse teks self te werk, en so hulle vermoë steeds verder te ontwikkel.

3 Hierdie uitkoms hou in dat die suksesvolle memorisering en reproduksie van bepaalde data nog nie die bereiking van die uitkoms is nie, maar dat dit slegs een van die moontlike middele tot die bereiking van die uitkoms kan wees. 
4 Ontleding bou in dat die betrokke vorm/konstruksie morfologies geanaliseer word.

5 Verklaring hou in dat die grammatiese rede vir 'n bepaalde vorm/konstruiksie vermeld word. 